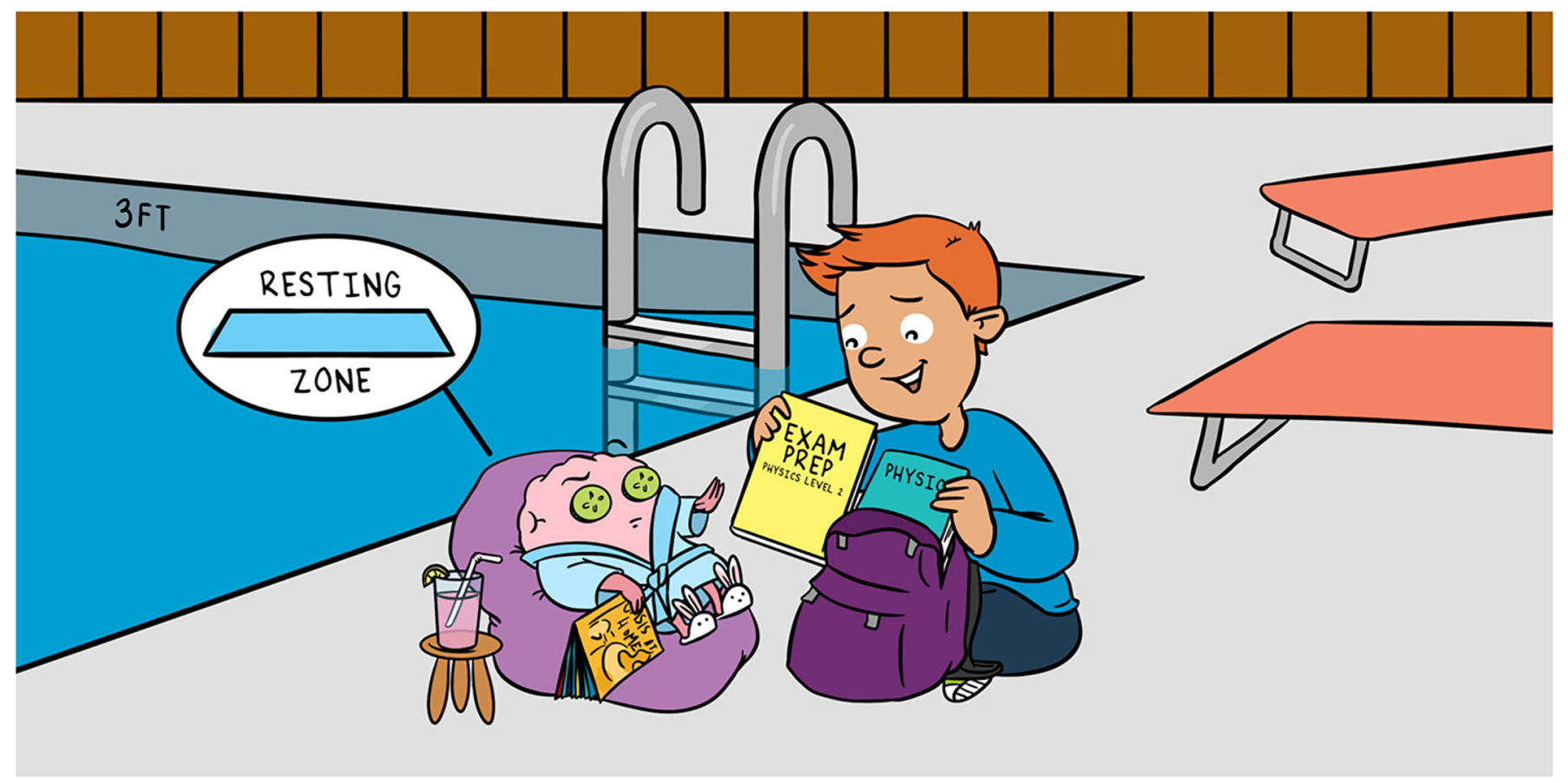

\title{
HOW STRESS AFFECTS US
}

Stephanie Ellis ${ }^{1}$, Vishnu P. Bhathe ${ }^{1}$, Christina Brennan ${ }^{1}$, Emily Moynes ${ }^{1}$, Kim G. C. Hellemans ${ }^{2}$ and Sean J. Landsman ${ }^{1^{*}}$

${ }^{1}$ Institute of Environmental and Interdisciplinary Science, Carleton University, Ottawa, ON, Canada

${ }^{2}$ Department of Neuroscience, Carleton University, Ottawa, ON, Canada

YOUNG REVIEWERS:

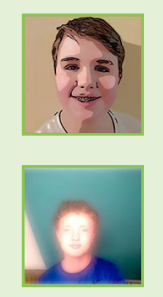

TORBEN

AGE: 12

CLAUDIO

AGE: 13
Stress is something we all experience in our daily lives. While we often think stress is a bad thing, some stress can be good for us, such as when we sense danger and run away from it. The moment the body senses something stressful, it immediately triggers a series of events to help us handle the stress. However, if our bodies are responding to stress all the time, it can be hard on our overall health. Therefore, it is important to maximize time spent exposing ourselves to "good" stress, minimize exposure to "bad" stress, and provide ourselves with lots of time to recover from any bad stress we might experience. Understanding how our bodies respond to stress and what conditions are best for our overall health is important for making healthy life choices.

\section{WE ALL EXPERIENCE STRESS}

Stress has always been a big part of human life and it influences us in a variety of situations. We can experience "good" stress, such as 
STRESSOR

Anything-could be something in the environment or a change within your body-that causes the body to adjust to an event or situation through the release of hormones.

\section{STRESS RESPONSE}

The process through which the body responds to a stressor. which typically involves emotional, mental, and physical components.

\section{AMYGDALA}

The brain's emotional control center, which detects stress.

\section{HYPOTHALAMUS}

The brain's command center, which sends messages throughout the body about detected threats.

1 Available online at: https://www. health.harvard. edu/stayinghealthy/ understandingthe-stress-response.

PITUITARY GLAND

The brain's threat response messenger. It releases hormones into the blood stream to send messages throughout the body.

\section{HORMONES}

Chemicals within the body that tell cells to do something. Hormones may increase heart rate or breathing, or may release a wave of energy, for example. during the exciting first day of school, or when we are competing in a race. But we also experience "bad" stress, such as stress that is experienced for a long time and without any opportunities for rest, such as during multiple-day exam periods at school. Highly traumatic and stressful events, such as experiencing war, can also have harmful effects on our health. Stress affects us differently depending on what is causing the stress, how long the stress lasts, and our own personal past experiences. This article is a crash course on how stress affects the brain, why we have a stress response, and the range of stresses we encounter.

What exactly IS stress? Well, first we must distinguish stress from a stressor. A stressor is any situation or event that requires the body to adjust, triggering the stress response (commonly called just "stress") is the body's response to the stressor [1]. The stress response includes emotions, such as feeling scared or overwhelmed. It also includes mental components, such as planning or thinking about how to escape the threat. Finally, the stress response has physical components, which include the release of certain substances in the body [1]. Individuals may respond to stressors differently. For example, one person may see cleaning his or her room as a chore or a stressful task, but another may find organizing and cleaning to be enjoyable. Peoples' responses to stressors may also be different because of many factors, including past experiences, beliefs, views, and even gender

\section{HOW STRESS AFFECTS THE BRAIN}

So, how does stress affect the brain and how does the brain respond? When the brain identifies a stressor, it immediately starts preparing to respond to it ${ }^{1}$. The amygdala is the part of the brain responsible for emotional control; it processes everything we see and hear, and if it identifies a danger or stressor, it sends a signal to another part of the brain, called the hypothalamus, about the danger. The hypothalamus is like a command center; its job is to communicate with the rest of the body. The hypothalamus sends messages about the threat throughout the body by communicating with the pituitary gland, which pushes hormones such as adrenaline and cortisol into the bloodstream. These hormones help the rest of the body to respond to the stressor. This process is described in Figure 1.

Think back to a dangerous event or an extreme stressor in your life. You might recall that your heart beat faster, your breathing sped up, and you felt a sudden rush of energy. All these effects happen due to the brain's response to a stressor. Your heart was working to push more blood to your muscles and vital organs. Your lungs opened to bring in as much oxygen as possible from every breath, to increase your 


\section{Figure 1}

The stress response begins when the brain recognizes a stressor. It then sends a message (hormone) to the hypothalamus, which in turn passes another message to the pituitary gland, which finally passes a message to the adrenal glands. The adrenal glands then tell the body to do something like breathe faster, increase the heart rate, or released stored energy. All these signals result in the body's stress response (Created with BioRender.com).

\section{ADRENAL GLANDS}

Structures in the body located above each kidney that release hormones into the bloodstream. These hormones help you do things like digest food and fight infections.

\section{HPA AXIS}

HPA stands for Hypothalamus, Pituitary (gland), and Adrenal (gland), which refers to areas in the body that interact with each other to control the release of important hormones. The hypothalamus and pituitary gland are both located in the brain while the adrenal glands are located above each kidney.

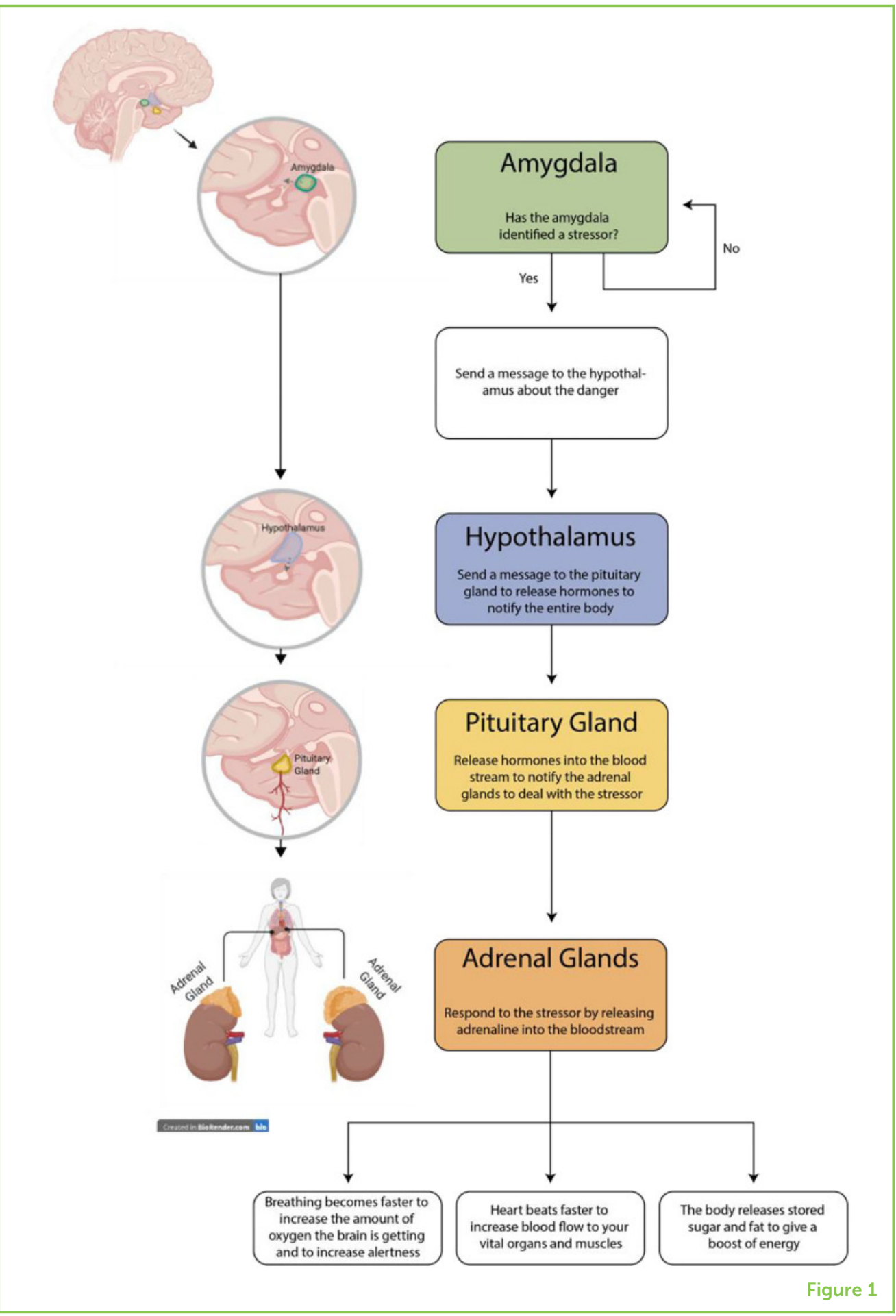

alertness. Your adrenal glands released adrenaline, a hormone that triggered your body to consume energy in the form of blood sugar and fats. Each of these responses helped your body cope with the stressful event ${ }^{1}$. This connected response between the hypothalamus, pituitary gland, and adrenal glands is often referred to as the HPA axis. 


\section{WHY DO WE HAVE A STRESS RESPONSE?}

Now that we understand how the brain and body respond to stress, we need to know why this response is important. During short-term, in-the-moment situations, the stress response is there to help us cope with any threat we are currently facing. The stress response works very quickly to spread the stress signal throughout the body so that we can react to it. The amazing speed at which the stress signal travels is the reason why some people can jump out of the way of a speeding car before they realize what is happening ${ }^{1}$ !

The stress response is what allows us to cope with stressors that are experienced over a short period of time, like minutes to hours. These so-called acute stressors function to activate the body to prepare for future challenges [2]. Facing and coping with mild to moderate stressors actually helps us develop coping skills, so that we can better face stressors in the future [1]! Short-term, mild stressful events can be considered "good stress," especially if we use positive coping strategies to combat the stressor, such as talking to a friend on the phone after a hard day at school.

On the other hand, we must also keep extreme stressors, or "bad stress," in mind. Extreme stressors are those that are either really severe in nature, like a car accident, or that last for a long time, like a chronic illness. Extreme stressors can result in long-lasting negative changes to our health. For example, extreme stressors can cause an overactive HPA response, in which the pituitary and adrenal glands pump out more stress hormones than they should, even in the face of minor stressors. Extreme stressors can also increase a person's chance of developing depression, anxiety, or post-traumatic stress disorder $[1,3,4]$. When extreme stressors happen early in life, such as during childhood or adolescence, they can cause problems with the body's overall regulation of the stress response, preventing the response from ending as it should $[1,2,4]$.

\section{WHAT IS THE STRESS SPECTRUM?}

You may wonder, "What is the proper balance of "good" stress vs. "bad" stress?" An ideal stress spectrum (Figure 2) can be used to figure out this balance. A spectrum refers to a range of things. For example, humans have a spectrum of skin tones, ranging from really light to really dark. A stress spectrum means that there are a range of responses the body takes when dealing with a stressor. There are three sections in the stress spectrum $[2,5]$. On one end of the spectrum, we have "good" stress, which can be beneficial for brain development. However, you cannot stay in the state of "good" stress constantly, as these events are generally short-lasting. On the opposite end of the spectrum we have "bad" stress. We want to keep our time in this section of the spectrum as short as possible, to reduce its 
Figure 2

To stay healthy, we must try to balance the stress response. In a perfect stress spectrum, we want to experience a lot of "good" stress and also try to remain in a state of low stress, when the body and mind can rest, for long periods of time. Because we cannot avoid "bad" stress, we want to keep the magnitude of "bad" stress to a minimum and stay in this part of the spectrum for as short a time as possible.

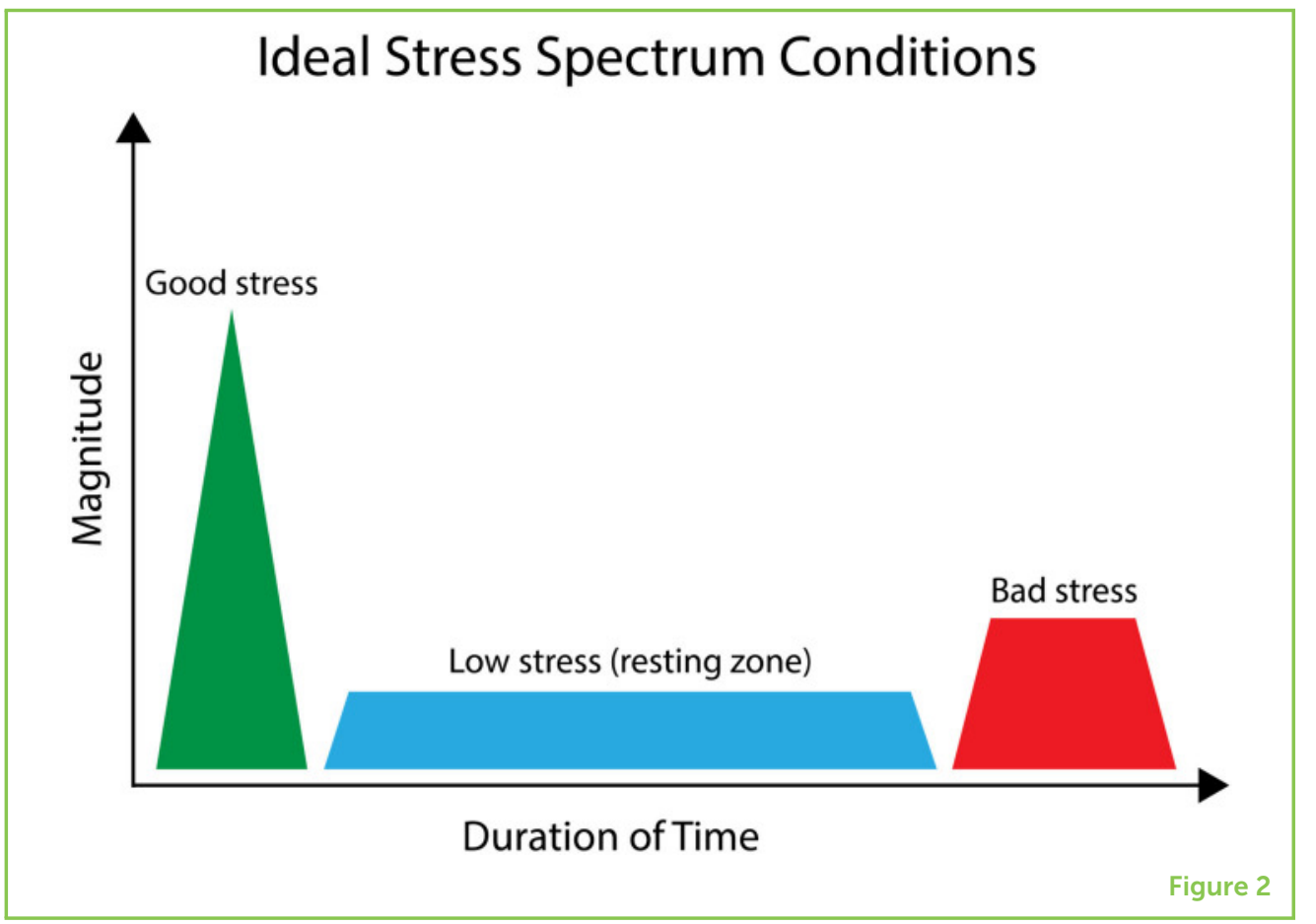

negative effects [5]. Finally, in the middle of the spectrum we have the low-stress section, in which we want to spend as much time as possible. In the low-stress section, we are in a state of good health and are giving the body a chance to recover from stress [5].

\section{MANAGING STRESS}

The stress spectrum can help you understand how to manage your stress. Finding activities that reduce stress, such as exercise or meditation, is an important life skill that can help us to reduce the impacts of bad stress on the body and brain. For example, exercise (particularly activities that require a lot of energy like running or playing hockey or soccer) is really good at pumping oxygen and glucose (sugar) up into the brain, which is what brain cells need to survive. In doing so, it also increases the production of certain proteins called "growth factors" that are responsible for nurturing these cells. Exercise literally helps build your brain! Scientists have also revealed that exercise releases natural "feel-good" chemicals that help relieve anxiety and stress. Mindfulness meditation also does something pretty cool in the brain: scientists believe that engaging in this practice regularly helps strengthen the activity of the prefrontal cortex, the part of the brain that is partly responsible for "calming down" the emotional centers of the brain.

In addition, having many healthy social connections can help to be a buffer against the negative effects of stress. Spending time with family, friends, and engaging in social activities is thought to increase production of oxytocin, a hormone often referred to as the "hugging 
hormone," due to its ability to increase social bonds. It is important to note that some things might work well for one person to reduce stress whereas something else works better for someone else. It is important to note that some things might work well for one person to reduce stress whereas something else works better for someone else.

\section{CONCLUSION}

Stress is all around us and is a part of life we cannot escape, but that does not mean it is all bad. The stress response can help us get through making a new friend or speaking in front of a crowd, but it also works to protect us from danger. The better we deal with stress, both as we grow into adults and throughout our adult lives, the better we can develop important life skills and coping strategies for handling future stress. Unfortunately, some stress can result in long-lasting negative effects, so it is important that everyone find ways to manage stress. Making the most of the "good" stress, minimizing the "bad" stress, and spending most of our time at low stress levels is critical for our overall health!

\section{REFERENCES}

1. Anisman, H. 2016. Health Psychology. 1st ed. London: Sage.

2. Dhabhar, F. S. 2009. Enhancing versus suppressive effects of stress on immune function: implications for immunoprotection and immunopathology. NeurolmmunoModulation. 16:300-17. doi: 10.1159/000216188

3. Heim, C., Newport, D. J., Mletzko, T., Miller, A. H., Nemeroff, C. B. 2008. The Link between childhood trauma and depression: insights from HPA axis studies in humans. Psychoneuroendocrinology. 33:693-710. doi: 10.1016/j.psyneuen.2008.03.008

4. Roberts, A.G., and Lopez-Duran, N. L. 2019. Developmental influences on stress response systems: Implications for psychopathology vulnerability in adolescence. Compreh. Psychiatry. 88:9-21. doi: 10.1016/j.comppsych.2018.10.008

5. Dhabhar, F. S. 2018. The short-term stress response - mother nature's mechanism for enhancing protection and performance under conditions of threat, challenge, and opportunity. Front Neuroendocrinol. 49:175-92. doi: 10.1016/j.yfrne.2018.03.004

SUBMITTED: 21 July 2020; ACCEPTED: 05 July 2021; PUBLISHED ONLINE: 04 August 2021.

EDITED BY: Silvia A. Bunge, University of California, Berkeley, United States

CITATION: Ellis S, Bhathe VP, Brennan C, Moynes E, Hellemans KGC and Landsman SJ (2021) How Stress Affects Us. Front. Young Minds 9:585831. doi: 10. 3389/frym.2021.585831 

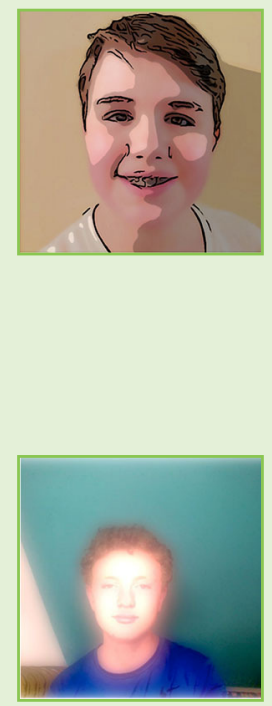

CONFLICT OF INTEREST: The authors declare that the research was conducted in the absence of any commercial or financial relationships that could be construed as a potential conflict of interest.

COPYRIGHT @ 2021 Ellis, Bhathe, Brennan, Moynes, Hellemans and Landsman. This is an open-access article distributed under the terms of the Creative Commons Attribution License (CC BY). The use, distribution or reproduction in other forums is permitted, provided the original author(s) and the copyright owner(s) are credited and that the original publication in this journal is cited, in accordance with accepted academic practice. No use, distribution or reproduction is permitted which does not comply with these terms.

\section{YOUNG REVIEWERS}

\section{TORBEN, AGE: 12}

Torben is motivated, talented, and intelligent. In school, he likes science, math, history, and geography. He loves to read books and is learning Spanish, French, and German. He plays piano and sings in several choirs. He has a special interest in neuroscience-related topics. His English teacher selected him to report on the COVID-19 crisis. To do so, he wrote a Spotify segment and interviewed his teachers about how the pandemic impacted teaching and learning. He enjoys biking and boyscout activities.

\section{CLAUDIO, AGE: 13}

I love to play basketball and skateboard, I love science and I love to read.

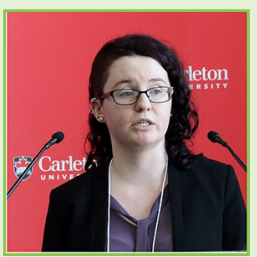

\section{AUTHORS}

\section{STEPHANIE ELLIS}

Stephanie is an undergraduate student in her final year of the Interdisciplinary Science and Practice program in Ottawa, Ontario, Canada. She is passionate about community engagement and figuring out how different systems work, from the human brain to computers. She was inspired by her teachers to continue searching for answers and to follow her passions at a young age.

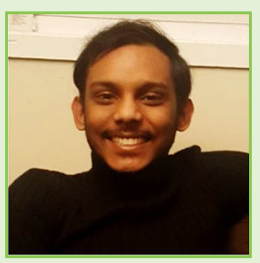

\section{VISHNU P. BHATHE}

Vishnu Bhathe recently graduated from Carleton University in Ottawa, Ontario, Canada with a Bachelor of Science degree. Ever since he was a child, he has been curious about science and how people use the lessons from science to better the world. He is also interested in entrepreneurship and aims to use scientific research to fuel innovation. In his free time, he likes to ride bikes, paint, read books, and exploring new things.

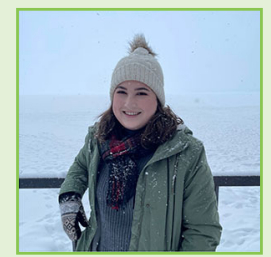

\section{CHRISTINA BRENNAN}

Christina Brennan is an undergraduate student at Carleton University in Ottawa, Ontario, Canada majoring in interdisciplinary science. She is especially interested in pursuing a career in science communication, and using the skills developed in her undergrad to bridge the gap between disciplines. Since she was 10 years old, 


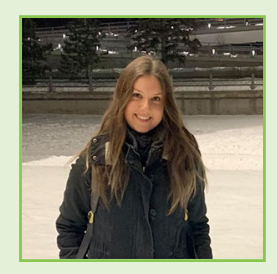

Christina has been designing floor plans of houses on graph paper and continues to do so today through 3D modeling. Aside from her academic goals, she hopes to 1 day design and build her own net zero home.

\section{EMILY MOYNES}

Emily is a fifth-year undergraduate student studying Environmental Science at Carleton University in Ottawa, Ontario, Canada. During her schooling, she completed an internship under the supervision of Dr. Steven Cooke on various fish-related projects, resulting in a publication in Transactions of the American Fisheries Society. She is currently completing her honors thesis with Dr. Thomas Sherratt on insect body toughness. She loves acquiring new knowledge and experiences in her field and hopes to 1 day obtain a job exploring animal behavior or working toward conservation-related initiatives.

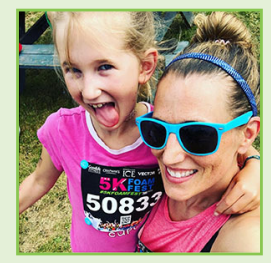

\section{KIM G. C. HELLEMANS}

Kim is a teaching professor and head of the department of neuroscience at Carleton University, located on the beautiful and unceded territory of the Algonquin peoples, in Ottawa, Ontario Canada. When not busy teaching, doing research on stress and mental health among university students, or telling other people what to do, Kim is an active runner, skier, skater, snowshoer, and all-around winter sport enthusiast! She also bakes a mean brownie and has two daughters that love to help her in the kitchen, do crafts, and keep her stress levels in the optimum zone.

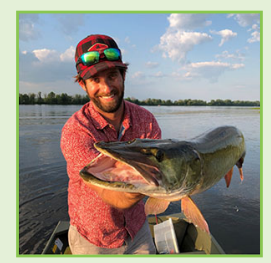

\section{SEAN J. LANDSMAN}

Sean is a teaching professor in the Interdisciplinary Science and Practice program at Carleton University in Ottawa, Ontario, Canada on the unceded territory of the Algonquin First Nation. He is a trained fisheries ecologist and studies how fish move about their environments as well as how people affect them. He is also a passionate science communicator and enjoys sharing his knowledge with anyone that will listen! In fact, it was this love of communicating fisheries science that led him to photography and specifically underwater photography. Sean loves to spend time outdoors, especially fishing and hiking, and enjoys tinkering in his basement making things out of wood. *sean.landsman acarleton.ca 